\title{
Open tibia fractures in HIV positive patients
}

\section{W.J.Harrison}

\begin{abstract}
Open tibia fractures are common injuries, particularly in developing countries.Pedestrian or bicycle to motor car contact is the most common mechanism. These injuries result in high morbidity and often long-term disability.
\end{abstract}

HIV infection complicates open fractures by raising the incidence of infectionin the open wound (5 of 7 patients in our series). This risk may be compounded if internal fixation techniques are used (5 of 12 HIV patients with

internal fixation of any open fracture). There is also a suggestion that HIV may delay bone union (4 of 7 patients

united at 6 months). External fixation offers an alternative method of fracture stabilisation. It avoids

the risks associated with putting metal-ware in the wound, but creates a new issue of pin track sepsis. We found that pin track infection was more common in patients with HIV, but the rate at which pins required removal was $7 \%$. We consider external fixation to be a lower-risk strategy than internal fixation in such patients but open fracture wound sepsis remains a problem. We have not yet demonstrated a difference in severity or frequency of complications in patients of low CD4 count, but logically one expects septic complications to increase as CD4 count falls. Antiretroviral medication decreases viral load and elevates the CD4 count.

Research is underway regarding potential effectiveness of such drugs in reducing wound and fracture healing complications. Above all, meticulous and timely all-round care is required to achieve satisfactory results in immunecompromised patients. This includes, debridement, bony stability, and soft-tissue reconstruction.

\section{Introduction}

Open tibia fractures are a common injury in developing countries, mostly from road trauma. These same countries, particularly those of sub-Saharan Africa, also face an epidemic of HIV with an estimated 25.4 million people HIV seropositive $^{1}$. The people group most at risk of HIV - the young mobile adult, is also the group most subject to road trauma. Treatment of open tibia fractures is often hampered by delays and inadequate resources and expertise.

We have undertaken three studies relevant to this topic: a prospective study of open tibia fractures comparing HIV positive and negative patients ${ }^{2}$, a prospective study of internal fracture fixation including cases in open fractures comparing wound infection for HIV positive and negative patients ${ }^{3}$, and a prospective study of pin track sepsis comparing HIV positive and negative patients ${ }^{4}$. This report aims to summarise the relevant data from these studies and draw some conclusions regarding current practice and remaining questions. The focus of debate is on wound sepsis and healing, with note also of fracture union. Final functional result has not been specifically assessed, but is largely consequent upon these two entities.

\section{Wound and pin-track sepsis}

In the first of our studies ${ }^{2}$ we looked at 27 cases of open tibia fracture (Gustilo ${ }^{5}$ grades 2 and 3) treated by debridement and monolateral external fixation. Of the 7 cases with
HIV disease, 5 resulted in deep sepsis of the open wound, compared to 4 out of $21 \mathrm{HIV}$ negative patients $(\mathrm{p}=0.020)$.

In the second study ${ }^{3}$ we looked at internal fixations in 12 patients with open fractures (not of the tibia) who had HIV disease. Wound infections occurred in $42 \%$ of the $12 \mathrm{HIV}$ positive patients compared to $11 \%$ in 27 controls $(p=0.084)$. Given the relatively small numbers involved, the impact of disease stage, and in particular of CD 4 count, cannot yet be established. In Hoekman's study ${ }^{6}, 3$ of 8 internal fixations of the tibia were complicated by infection - and this was in closed injuries. Our third study ${ }^{4}$ considered pin track sepsis assessed by the Checketts ${ }^{7}$ score. It considered 15 external fixators in patients with HIV disease compared to 35 fixators in HIV negative controls. There were significantly more pin infections requiring pharmaceutical or surgical intervention in HIV positive patients $(\mathrm{p}=0.001)$. However severe pin track infections requiring surgical re-siting of pins occurred in only $7 \%$ of the fixators. Thus, external fixators are in themselves relatively safe devices for patients with HIV disease.

\section{Union}

In our prospective study on open tibia fractures ${ }^{2}, 3$ of the 7 patients with HIV disease had ununited fractures at 6 months. This compared with only 1 of 21 fractures in HIV negative controls, which was known to be ununited at 6

months. In the internal fixation study ${ }^{3}$, fractures in HIV positive patients appeared to heal well after surgery. However, at presentation $33 \%$ of 55 non union cases were found to be HIV positive, compared to $16 \%$ of 111 patients presenting with fresh fractures. Whilst the association with non-union in the open fracture series may be attributable to small numbers or to an effect of sepsis causing the delay in union, the non-union series in the internal fixation study suggest that HIV disease may have a direct association with non-union, perhaps mediated by $\mathrm{n}$ impaired inflammatory response ${ }^{8}$ ? This is not conclusive as factors such as nutrition and lifestyle (tobacco smoking) have not been evaluated.

\section{Current management advice}

What is clear is that whilst severe open tibial fractures are challenging to treat in any patient, for the immune compromised patient, a poor outcome may occur in the majority of cases. These are currently unsolved injuries. One might conclude that since internal fixation of open fractures in HIV positive patients has a high wound sepsis rate, and since external fixation is relatively safe, then all such cases should be treated with external fixators?

The problem with this approach is that our data revealed that while the pin tracks were satisfactory, the open wounds still mostly got infected using such a protocol.

The stability offered by nailing is greater than that of external fixation, and this may assist in preventing sepsis. It is also advantageous for fracture healing. Unreamed nailing is relatively biological in minimising damage to blood supply. The concern is the presence of an implant the whole length of the tibia, whereby wound sepsis may spread the length of the bone. We do not yet have the answer to this dilemma. What is clear is that treatment must be aggressive and meticulous. We have advanced in availability of ARVs, vacuum assisted closure dressings, and locked tibial Sign nails since our original study. For those of us who work in 
areas of high HIV seroprevalence and where resources allow I now suggest the following protocol:

- on day 1 broad spectrum intravenous antibiotics and an emergency

debridement with external fixation and wound left open and treated with vacuum suction dressing.

- On day 2 the patient should be counselled and tested for HIV and CD4 count undertaken in positive patients.

- On day 3 the patient should return to theatre. If the wound is clean and the CD 4 greater than 350 cells $/ \mathrm{mm} 3$, the external fixation should be replaced with a biological internal fixation (e.g IM locked nail) and the wound closed by flaps or grafts without tension.

o If the wound is dirty, it should be re-debrided, left open, and stability maintained with the external fixator.

o ARVs should be commenced if CD4 is less than 350cells/ $\mathrm{mm} 3$

I recommend intravenous antibiotics until wound closure at 48 hours. These should be broad spectrum to cover likely contaminants of the injury. We use cefazolin or cefuroxime.

We do not yet have data to support that such a strategy would improve outcomes, but it seems a logical extension of data collected so far, and experience from research with healthy individuals where intramedullary locked nails have given best results ${ }^{9}$.

\section{Remaining questions}

The place of the CD4 count is still uncertain. Logic suggests that patients with low CD4 counts are at highest risk of deep wound sepsis, but this has not yet been shown clinically. All this research emanates from an era before antiretroviral therapy. This treatment reduces viral loads, elevates CD4 count, and boosts host immunity. It is reasonable to expect that results will improve in the presence of such therapy. However, many patients eligible for ARVs are not under treatment at the time of injury and ARVs take time to restore host immunity. Thus the effect of initiating ARVs at the time of injury is also uncertain. Sepsis remains the major concern, if success in preventing infection can be achieved, then fracture union may become an issue. In this regard the influence of mechanical factors is likely to relate to what has been learned in healthy hosts8, but biological influences including reaming and bone grafting may also vary in the patient with HIV disease.

\section{References}

1. No authors listed. Joint United national Programme on HIV/ AIDS(UNAIDS) \& World health organisation (WHO), AIDS epidemic update December 2004: UNAIDS/ 04.45E, ISBN 929173390 3. http:// www.unaids.org/wad2004/Eplupdate2004_html_en/epi04_00_en.

htm

2. Harrison WJ, Lewis CP, Lavy CBD. Open fractures of the tibia in HIV positive patients: a prospective controlled single-blind study. Injury 2004;35:852-6

3. Harrison WJ, Lewis CP, Lavy CBD. Wound healing after implantsurgery in HIV-positive patients. J Bone Joint Surg [Br] 2002;84-B:802- 6

4. Norrish AR, Lewis CP, Harrison WJ. Pin-track infection in HIVpositive and HIV-negative patients with open fractures treated by external fixation. J Bone Joint Surg [Br] 2007;89-B:790-3

5. Gustilo RB, Anderson JT. Prevention of infection in the treatment of one thousand and twety-five open fractures of long bones: retrospective and prospective analyses. J Bone Joint Surg [Am] 1976;58-A:453-8

6. Hoekman P, van de Perre P, Nelissen J et al. Increased frequency of infection after open reduction of fractures in patients who are seropositive for human immunodeficiency virus. J Bone Joint Surg [Am\} 1991;73-A:675-9

7. Checketts RG, Otterburn M, MacEachern G. Pin track infection: definition, incidence and prevention. Int JOrth Trauma 1993;3(Suppl):1618

8. Richardson J, Hill AM, Johnston CJC, McGregor A, Norrish AR,Eastwood D, Lavy CBD. Fracture healing in HIV-positive populations. J Bone Joint Surg [Br] 2008;90-B:988-94

9. Giannoudis PV, Papakostidis C, Roberts C. A review of the management of open fractures of the tibia and femur. J Bone Joint Surg [Br]2006;88-B:281-289 